\section{Small intestinal absorption and tolerance of enteral nutrition in acute colitis}

Enteral nutrition is not widely accepted in the management of severe colitis, partly because of the reported impaired absorption in the small intestine. ${ }^{1}$ Transit of food through the small intestine, however, is prolonged in patients with active ulcerative colitis, ${ }^{2}$ which should enhance small bowel absorption by increasing the time of contact between food and small bowel mucosa.

We have re-evaluated small intestinal absorption in patients with severe colitis and examined the tolerance of enteral nutrition as assessed by stool output, symptoms, and clinical outcome.

\section{Patients, methods, and results}

Of the nine consecutive patients admitted to our unit between April 1985 and August 1986 who fulfilled criteria for severe non-specific colitis, ${ }^{3}$ seven had total ulcerative colitis and two Crohn's colitis. The last two patients had no radiological evidence of small bowel disease.

On day 1 oral fluids and food were withdrawn and fluid balance maintained intravenously. On day 2 the intravenous infusion was stopped, a fine bore nasogastric tube introduced, and Fortison Standard solution infused continuously at $40 \mathrm{ml} /$ hour on day 2 and $80 \mathrm{ml} /$ hour from days 3 to 7 . Throughout the study all patients received $16 \mathrm{mg}$ prednisolone sulphate intravenously four times a day and their stool output was collected. Clear water was allowed from day 3 onwards but all other food and drink were prohibited until enteral feeding was finished. From day 8 patients were allowed an ordinary diet. A $5 \mathrm{~g}$ xylose test was carried out on days 3 and $7{ }^{4}$ The fat content of stools passed from day 3 to day 8 was measured. Patients scored the severity of seven important symptoms on a visual analogue scale on alternate days. Results were analysed by Wilcoxon's rank sum test.

In eight of nine patients xylose absorption was normal. On day 3 the mean one hour blood xylose value was 1.1 (SEM 0.1$) \mathrm{mmol} / \mathrm{h}$ and mean five hour urinary output $28 \%$ (SEM $3 \%$ ) with almost identical results in every patient on day 7 . In the one patient with subtotal Crohn's colitis the one hour blood xylose value $(0.56 \mathrm{mmol} / \mathrm{l})$ and five hour urinary excretion $(17 \%)$ were reduced. Faecal fat excretion was normal in all patients (median 9 (range 5-14) mmol/day).

Clinical course during steroid treatment and with enteral nutrition from day 2 to day 7. Figures are means

\begin{tabular}{|c|c|c|c|c|c|}
\hline & \multicolumn{5}{|c|}{ Day } \\
\hline & 1 & 3 & 5 & 7 & 10 \\
\hline $\begin{array}{l}\text { Stool weight (g) } \\
\text { Stool frequency } \\
\text { Anorexia score } \\
\text { Urgency score } \\
\text { Pain score } \\
\text { Tenesmus score } \\
\text { Erythrocyte sedimentation rate }\end{array}$ & $\begin{array}{r}740 \\
7 \cdot 9 \\
8 \cdot 1 \\
7 \cdot 2 \\
7 \cdot 0 \\
5 \cdot 8\end{array}$ & $\begin{array}{l}430^{\star} \\
5 \cdot 7 \star \\
6 \cdot 0 \\
3 \cdot 0 \\
5 \cdot 0 \\
4 \cdot 0\end{array}$ & $\begin{array}{l}340^{\star \star} \\
4.5 \star \star \star \star \\
0.9 \\
1.5 \\
2.0 \\
2.0\end{array}$ & $\begin{array}{l}270^{\star \star \star} \\
3.9 \star \star \star \star \\
0.5 \\
0.8 \\
2 \cdot 0 \\
1.0\end{array}$ & $\begin{array}{l}370 \\
4.3 \\
0 \\
0.5 \\
1 \cdot 2 \\
0.8\end{array}$ \\
\hline $\begin{array}{l}\text { (mm in first hour) } \\
\text { Albumin }(g / 1) \\
\text { Weight loss }(\%)\end{array}$ & $\begin{array}{l}54 \\
28 \\
10 \cdot 0\end{array}$ & $\dot{-}$ & $\bar{z}$ & $\begin{array}{l}39 \\
32^{\star} \\
7 \cdot 0^{\star}\end{array}$ & $\bar{z}$ \\
\hline
\end{tabular}

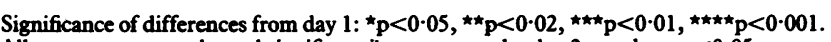
All symptom scores showed significant improvement by day 3 to at least $p<0.05$.

During enteral feeding there was a significant reduction in daily stool weight and frequency when compared with the starvation period of day 1 (table). After starting an ordinary diet there was a small but insignificant rise in stool output. A significant improvement was seen in all seven symptoms between day 1 and day 7 . The preceding weight loss was reversed and serum albumin concentration increased.

\section{Comment}

The daily intake on enteral feeding was $80 \mathrm{~g}$ fat, $80 \mathrm{~g}$ protein, and $8.4 \mathrm{MJ}$ $(2000 \mathrm{kcal})$ energy, which, given the recorded anorexia, was certainly more than would be consumed in the first few days as normal food. Both fat and xylose were absorbed normally. This normal small intestinal function together with slow small bowel transit ${ }^{2}$ explains the satisfactory tolerance of enteral nutrition. The initial high stool outputs during starvation show that in severe ulcerative colitis the diarrhoea is secretory, and as inflammation improved in response to steroids stool output fell rapidly despite feeding. Concomitant with the fall in stool output the symptoms of urgency, tenesmus, and pain had largely resolved by day 7 . All patients remitted without surgery, the mean inpatient stay being 21 days.

Oral feeding has already been shown to have no adverse effect on clinical outcome. ${ }^{5}$ The nutritional improvement in our study was comparable to that achieved by parenteral nutrition. ${ }^{5}$ Reports of malabsorption in ulcerative colitis or fears of making diarrhoea worse should not prevent doctors using this cheaper and safer route of nutritional supplementation, and starvation need no longer be a routine feature of protocols for the management of severe colitis.

1 Salem SN, Truelove SC. Small intestinal and gastric abnormalities in ulcerative colitis. Br Med $\mathcal{J}$ 1965;:827-31.

2 Rao SSC, Read NW, Holdsworth CD. Gastrointestinal transit and stool output in the pathophysiology of diarrhoea in ulcerative colitis (UC). Clin Sci 1986;71:41P.

3 Truelove SC, Witts LJ. Cortisone in ulcerative colitis. Final report on a therapeutic trial. BrMed $\mathcal{f}$ 1955;ii:1041-8.

4 Heaney MR, Culank LS, Montgomery RD, Sammons HG. Evaluation of xylose absorption as measured in blood and urine: a one hour blood xylose screening test in malabsorption. Gastraenterology 1978;75:393-400.

5 Dickinson RJ, Ashton MG, Axon ATR, Smith RC, Yeung CK, Hill GL. Controlled trial of intravenous hyperalimentation and total bowel rest as an adjunct to the therapy of acute colitis. Gastroenterology 1980;79:1199-204.

(Accepted 10 fuly 1987)

Gastrointestinal Unit and Department of Clinical Chemistry, Royal Hallamshire Hospital, Sheffield S10 2JF

S S C RAO, MRCP, clinical research fellow

C D HOLDSWORTH, MD, FRCP, consultant physician

A R W FORREST, MRCP, MCB, consultant in clinical chemistry

Correspondence to: Dr Holdsworth, gastrointestinal unit, floor J.

\section{Effect of fear of AIDS on sharing of injection equipment among drug abusers}

Because drug users who inject are a high risk group for the acquired immune deficiency syridrome (AIDS) ${ }^{1}$ there have been calls to provide them with sterile injection equipment to eliminate the need to share syringes and thus reduce the spread of AIDS. ${ }^{23}$ There is, however, no evidence that this measure will be effective because little is known of current injection practices and how they have changed since the risk of AIDS became imminent.

Patients, methods, and results

A questionnaire investigating the injection practices of drug abusers was completed anonymously by all of the 232 drug users attending three London drug dependence treatment units in January 1987.

Sex was recorded for 219 respondents, of whom $140(64 \%)$ were men. Age was recorded in 222 cases: $78(35 \%)$ were aged $20-29,115(52 \%)$ were aged $30-39$, and $6(3 \%)$ were aged under 20 . Two of the respondents $(1 \%)$ were known to be carriers of the AIDS virus, but most had not been tested.

Of the 232 respondents, 205 were receiving treatment, which for 184 patients included a prescription for methadone; 27 were undergoing pretreatment assessment. In all, 204 respondents $(89 \%)$ were using drugs (excluding alcohol and cannabis and including prescribed methadone), of whom $90(44 \%)$ did not inject at all, $51(25 \%)$ injected only occasionally, and $63(31 \%)$ took drugs mainly or exclusively by injection. Only 20 respondents had never injected drugs. The table shows the extent to which injection equipment had been and was being shared by the 212 who injected drugs. Many who had formerly shared equipment no longer did so, and although 64 still allowed others to use their syringes, only 19 used other people's dirty equipment.

Of 150 respondents who thought that they had received sufficient information about AIDS, $124(83 \%)$ had consequently changed their drug using habits, including 35 who had stopped injecting and 52 who had stopped sharing. Of the 205 receiving treatment, $160(78 \%)$ thought that this had helped them to make beneficial changes in their drug using habits. Most (198; 85\%) though that stopping injecting would be easier if treatment was available more quickly. Though $105(45 \%)$ believed that providing syringes would encourage non-injectors to start injecting, $109(47 \%)$ disagreed. Twenty one $(21 \%)$ of the 99 respondents who were not regular injectors admitted that they would start injecting if sterile equipment was freely available.

\section{Comment}

Despite the risk of AIDS a hard core of drug abusers continue to share syringes. There are two overlapping groups: those who use syringes after someone else and those who allow others to use their syringes. The 
Sharing of injection equipment by 212 drug abusers

\begin{tabular}{lrc}
\hline & $\begin{array}{c}\text { No (\%) using injection } \\
\text { equipment after } \\
\text { someone else }\end{array}$ & $\begin{array}{c}\text { No (\%) allowing } \\
\text { someone else to use } \\
\text { injection equipment } \\
\text { after themselves }\end{array}$ \\
\hline Never & $35(16)$ & $61(29)$ \\
Previously but no longer & $158(75)$ & $87(41)$ \\
Yes but only with someone well known & $11(5)$ & $40(19)$ \\
Yes with anyone & $8(4)$ & $24(11)$ \\
\hline Total & $212(100)$ & $212(100)$ \\
\hline
\end{tabular}

discrepancy in numbers between the two groups suggests that those in the second group have been sharing with drug abusers not receiving treatment and thus a policy of providing clean syringes should logically extend to those not attending treatment units, although this might encourage more drug abusers to start injecting.

Because sharing of syringes is associated with a feeling of community among drug users and not only with a shortage of needles, ${ }^{4}$ it is unlikely to cease if syringes become more easily available. In addition, a drug user may forget his or her own syringe or be tempted to have an unplanned fix. It is not surprising, therefore, that infection with the AIDS virus among drug users in Italy has risen sharply despite the free availability of syringes. ${ }^{5}$

Fear of AIDS, the educational measures adopted so far, and treatment at specialist units already seem to have reduced injecting and sharing among clinic attenders, and this must be taken into account in any future assessment of the effect of policy initiatives. The question to be addressed will be the extent to which sharing may be reduced further by providing free syringes.

1 Friedland GH, Harris C, Butkus-Small C, et al. Intravenous drug abusers and the acquired immune deficiency syndrome (AIDS). Arch Intern Med 1985;145:1413-7.

2 Andreyev HJN. Selling syringes to drug addicts. Lancet 1985;ii:1192-3.

3 Scottish Home and Health Department. HIV infection in Scotland. Edinburgh: Scottish Home and Health Department, 1986.

4 Black JL, Dolan MP, DeFord HA, et al. Sharing of needles among users of intravenous drugs. N Englf Med 1986;314:446-7.

5 Moss AR. AIDS and intravenous drug use: the real heterosexual epidemic. Br Med f 1987;294: $389-90$.

(Accepted 10 fuly 1987)

St George's Hospital Medical School, London SW17 ORE

A H GHODSE, PHD, FRCPSYCH, professor, department of psychiatry

G TREGENZA, MB, CHB, assistant psychiatrist, section of psychiatry of addictive behaviour

M LI, MD, WHO research fellow, section of psychiatry of addictive behaviour

Correspondence to: Professor A H Ghodse, Department of Psychiatry, St George's Hospital Medical School, Cranmer Terrace, London SW17 0RE.

\section{Arthropathy in a patient with cystic fibrosis taking ciprofloxacin}

Ciprofloxacin is a broad spectrum antibiotic available as tablets that has good activity against Pseudomonas aeruginosa. Though used for recurrent chest infection in adults with cystic fibrosis, ${ }^{1}$ it is not recommended for under 18 year olds, mainly because of arthropathy with cartilage erosion seen in young animals given the drug or related compounds (G Schlüter, in proceedings of first international ciprofloxacin workshop, Leverkusen (Bayer), 6-8 November 1985, pp 61-70). We report the case of a 16 year old girl with cystic fibrosis and advanced lung disease who received ciprofloxacin on a named patient basis. She developed arthropathy of both knees after three weeks, which resolved completely within two weeks of stopping the drug.

\section{Case report}

This girl had cystic fibrosis diagnosed on the basis of sweat tests at 15 month and 7 years, a positive family history (a brother had died of the disease at 13), and typical clinical findings. In January 1986, at the age of 16 , she had an exacerbation of respiratory symptoms. Sputum yielded a heavy growth of $P s$ aeruginosa, and after an unsatisfactory response to two weeks of tobramycin and azlocillin she was prescribed oral ciprofloxacin $750 \mathrm{mg}$ twice daily (body weight $33 \mathrm{~kg}$ ). Oral flucloxacillin, stanozolol $2.5 \mathrm{mg}$ daily, gentamicin and carbenicillin by inhalation, and standard vitamin and pancreatic supplements were continued as before. On review at 18 days sputum characteristics had improved, she had gained $2 \mathrm{~kg}$, and the white cell count had returned to normal. Serum urea, electrolyte, and glucose concentrations, liver function, prothrombin time, and results of urine analysis, obtained before ciprofloxacin and repeated at 18 days, were normal.

At 20 days she felt less well, reporting pain in both knees, worse on standing, and discomfort in one wrist. Examination showed warmth and swelling of both knees with effusion in one and a small popliteal cyst in the other; movement was full but painful. No other joint abnormalities were found and there was no rash There was no improvement after two days' bed rest, and ciprofloxacin was stopped. She was not given anti-inflammatory agents. Inflammation began to decrease after a further two days, and by two weeks all abnormalities had resolved.

Results of investigations five days after stopping ciprofloxacin were: sedimentation rate $50 \mathrm{~mm}$ in first hour; positive rheumatoid factor titre $(1 / 64)$ and negative viral screens; serum negative for antinuclear factor, mitochondrial antibody, smooth muscle antibody, and autoantibodies to extractable nuclear antigens; evidence of circulating immune complexes shown by monoclonal rheumatoid factor binding assay $(65 \%$; normal $<15 \%)$; and serum total haemolytic complement normal. All values were similar four months later, when serum urate concentration was also normal and she was negative for HLA-B27. Serum IgG concentration was $35 \cdot 4 \mathrm{~g} / \mathrm{l}$ (normal 6-15), IgA $9 \cdot 46 \mathrm{~g} / \mathrm{l}(1 \cdot 0-4 \cdot 8)$, and $\mathrm{IgM} 1 \cdot 85 \mathrm{~g} / \mathrm{l}$ $(0 \cdot 5-2 \cdot 5)$.

Radiographs of the knees during the arthropathy were normal and, in common with radiographs of the hands and feet, four months later showed no periostitis or erosion of articular cartilage.

\section{Comment}

Arthropathy occurs in 7-8\% of adolescents and adults with cystic fibrosis, usually affecting knees and ankles. ${ }^{2}$ Causes are cystic fibrosis arthropathy, hypertrophic pulmonary osteoarthropathy, and miscellaneous. The transient synovitis of cystic fibrosis arthropathy is usually recurrent over weeks or months. Our patient had no arthropathy before ciprofloxacin and none developed during the ensuing 18 months. There was no radiological evidence of hypertrophic pulmonary osteoarthropathy, though we accept that, rarely, clinical features may exist before $x$ ray changes. ${ }^{2}$

Among other causes of arthropathy in cystic fibrosis hyperuricaemia, pancreatitis, and viral infections either were not suggested clinically or were excluded by investigation. Rheumatoid factor is found in many chronic pulmonary infections, including cystic fibrosis. ${ }^{23}$ Our patient's serum was not tested before the arthropathy. Subsequently she remained positive for rheumatoid factor but did not fulfil diagnostic criteria for rheumatoid arthritis. ${ }^{4}$ Circulating immune complexes were detected but these are commonly found in chronic pulmonary infections, ${ }^{3}$ being attributed to bacterial antigens rather than autoantigens.

The evidence suggests that our patient's arthropathy was due to ciprofloxacin rather than another cause. Unlike the arthropathy seen in young animals given quinolone compounds (though in higher dosage; G Schlüter, cited above) there was no erosion of joint cartilage. The manufacturer reports that between May 1983 and December 1985, 75 patients aged under 18 received 83 courses of ciprofloxacin for many diagnoses. Of these patients, 49 with cystic fibrosis received 56 courses. Two girls aged 14 and 10 with cystic fibrosis developed arthralgia: knees were affected in both patients and ankles in one after treatment for one and three months, respectively. Both girls recovered fully soon after stopping ciprofloxacin (Bayer, personal communication).

We thank Mr N Amos, of the department of rheumatology, for helpful discussions.

1 Hodson ME, Roberts CM, Rutland RJA, Smith MJ, Batten JC. Ciprofloxacin compared with conventional intravenous treatment for Pseudomonas aenuginosa infection in adults with cystic fibrosis. Lancet 1987; i:235-7.

2 Phillips BM, David TJ. Pathogenesis and management of arthroplasty in cystic fibrosis. $\mathcal{J} R$ So Med 1986;79(suppl 12):44-60.

3 Bartfeld $\mathrm{H}$. Distribution of rheumatoid factor activity in non-rheumatoid states. Ann NY Acad Sc 1969;168:30-40.

4 American Rheumatism Association. Diagnostic criteria for rheumatoid arthritis. 1958 Revision. Ann Rheum Dis 1959;18:49-51.

(Accepted 10 fuly 1987)

University Hospital of Wales, Heath Park, Cardiff CF4 4XW

M ALFAHAM, MRCP, research fellow in cystic fibrosis, department of child health

MARY E HOLT, MD, MRCP, senior registrar, department of rheumatology

MARY C GOODCHILD, MD, DCH, associate specialist in cystic fibrosis, department of child health

Correspondence to: Dr Alfaham. 